\title{
Malpighiaceae na Reserva Biológica do Alto da Serra de Paranapiacaba, Santo André, SP, Brasil
}

\author{
Gisele Gomes Nogueira Alves ${ }^{1,2}$ e Renata Sebastiani ${ }^{3,4}$
}

Recebido: 22.10.2014; aceito: 24.04.2015

\begin{abstract}
Malpighiaceae at Reserva Biológica do Alto da Serra de Paranapiacaba, Santo André, São Paulo State, Brazil). Reserva Biológica de Paranapiacaba has an important remnant of Atlantic Forest in São Paulo metropolitan region, located at Serra do Mar. A taxonomic treatment on Malpighiaceae from Reserva Biológica do Alto da Serra de Paranapiacaba is presented. We identified five genera and eight species: Byrsonima myricifolia Griseb., Heteropterys intermedia (A. Juss.) Griseb., H. nitida (Lam.) Kunth, H. patens (Griseb.) A. Juss., H. thyrsoidea (Griseb.) A. Juss., Mascagnia sepium (A. Juss.) Griseb., Hiraea fagifolia (D.C.) A. Juss, and Tetrapterys phlomoides (Spreng.) Nied. An identification key, descriptions, and illustration of the fruits of species are included.
\end{abstract}

Keywords: Atlantic Forest, Heteropterys, Serra do Mar, taxonomy

RESUMO - (Malpighiaceae na Reserva Biológica do Alto da Serra de Paranapiacaba, Santo André, SP, Brasil). A Reserva Biológica de Paranapiacaba possui um importante remanescente de Floresta Atlântica na região metropolitana de São Paulo, localizado na Serra do Mar. Este trabalho apresenta o tratamento taxonômico da família Malpighiaceae da Reserva Biológica do Alto da Serra de Paranapiacaba. Foram reconhecidos cinco gêneros e oito espécies: Byrsonima myricifolia Griseb., Heteropterys intermedia (A. Juss.) Griseb., H. nitida (Lam.) Kunth, H. patens (Griseb.) A. Juss., H. thyrsoidea (Griseb) A. Juss., Hiraea fagifolia (D.C.) A. Juss., Mascagnia sepium (A. Juss.) Griseb. e Tetrapterys phlomoides (Spreng.) Nied. O trabalho contém chave de identificação, descrições e ilustração dos frutos das espécies.

Palavras-chave: Floresta Atlântica, Heteropterys, Serra do Mar, taxonomia

\section{Introdução}

Malpighiaceae possui distribuição pantropical, incluindo 75 gêneros e cerca de 1.300 espécies (Davis $\&$ Anderson 2010, Anderson, 2013). O centro de diversidade do grupo concentra-se na América do Sul em áreas de Cerrado, sendo no Brasil representado por 44 gêneros e 561 espécies (Anderson 1979, Mamede et al. 2015). A família é caracterizada pela presença de cinco pétalas unguiculadas, alternas às sépalas do cálice, que em geral portam um par de elaióforos na base. Na maioria das espécies, o androceu apresenta dez estames e o gineceu três carpelos uniovulados, cada um contendo um estilete. Os frutos são esquizocárpicos, podendo possuir alas, ou drupáceos (Sebastiani \& Mamede 2010).
De acordo com Mamede et al. (2015), são reconhecidas 198 espécies de Malpighiaceae no domínio Floresta Atlântica no Brasil, incluindo as diversas fitofisionomias relacionadas, tais como Floresta Estacional Semidecidual e Floresta Ombrófila Densa. Desse total, 75 espécies estão também presentes no Estado de São Paulo nesse tipo de domínio. Na região da Grande São Paulo existem vários remanescentes de Floresta Atlântica, dentre eles o Núcleo Curucutu, pertencente ao Parque Estadual da Serra do Mar e a Serra da Cantareira, que integra o Parque Estadual da Cantareira. O Distrito de Paranapiacaba, localizado no município de Santo André, abriga um dos primeiros fragmentos de Floresta Atlântica na região metropolitana a ser reconhecido e preservado em uma Unidade de

1. Universidade Paulista, Instituto de Ciências da Saúde, Rua Apeninos, 127, 01533-000 São Paulo, SP, Brasil

2. Universidade de São Paulo, Instituto de Biociências, Departamento de Botânica, Laboratório de Sistemática Vegetal, Rua do Matão, 277 , 05508-090 São Paulo, SP, Brasil

3. Universidade Federal de São Carlos, Centro de Ciências Agrárias, Campus de Araras, Via Anhanguera 174, Caixa Postal 153, 13600-970 Araras, SP, Brasil

4. Autor para correspondência: renatasebastiani@ig.com.br 
Conservação (Lopes et al. 2009). Por se localizarem próximos de centros urbanos, esses remanescentes sofrem intensa pressão antrópica e consequentemente podem ter sua biodiversidade ameaçada (Kirizawa et al. 2009).

De acordo com Kirizawa et al. (2009), oito espécies de Malpighiaceae ocorrem na Reserva Biológica do Alto da Serra de Paranapiacaba (Distrito de Paranapiacaba): Byrsonima myricifolia Griseb., Heteropterys intermedia (A. Juss.) Griseb., H. nitida (Lam.) D.C., H. patens (Griseb.) A. Juss., H. thyrsoidea A. Juss., Mascagnia sepium (A. Juss.) Griseb., Stigmaphyllon arenicola C.E. Anderson e Tetrapterys phlomoides (Spreng.) Nied. Considerando a ação antrópica que fragmentos florestais próximos a regiões metropolitanas sofrem somado à escassez de trabalhos de cunho taxonômico de Malpighiaceae na Floresta Atlântica de São Paulo, tornam-se necessários estudos que contribuam para a avaliação da atual diversidade biológica da Reserva Biológica de Paranapiacaba. Dessa forma, o presente estudo teve como objetivo realizar um levantamento taxonômico da família Malpighiaceae para a Reserva Biológica do Alto da Serra de Paranapiacaba a fim de complementar os dados disponíveis para esta unidade de conservação.

\section{Material e métodos}

O Distrito de Paranapiacaba possui um fragmento florestal inserido no domínio da Floresta Atlântica localizado no topo da Serra do Mar, constituído por florestas tropicais ombrófilas densas e sempre verdes (Coutinho 2009). Atualmente, este distrito abriga três Unidades de Conservação: a Reserva Biológica do Alto da Serra de Paranapiacaba, administrada pelo Instituto de Botânica de São Paulo, o Parque Natural Municipal Nascentes de Paranapiacaba, administrado pela Prefeitura Municipal de Santo André, além de uma pequena parcela do Parque Estadual da Serra do Mar, administrado pelo Instituto Florestal (Mendes \& Sebastiani 2012). A Reserva Biológica do Alto da Serra de Paranapiacaba é a única Unidade de Conservação de caráter restritivo situada muito próxima à região litorânea paulista, entre as coordenadas 23046'00"$23^{\circ} 47^{\prime} 10^{\prime \prime} \mathrm{S}$ e $46^{\circ} 18^{\prime} 20^{\prime \prime}-46^{\circ} 20^{\prime} 40^{\prime \prime} \mathrm{W}$, ligeiramente ao sul do Trópico de Capricórnio, com altitudes variando entre 750 e 891 metros e clima predominantemente tropical úmido (Gutjahr \& Tavares 2009).

Foram realizadas cerca de 20 visitas à Reserva Biológica do Alto da Serra de Paranapiacaba e seu entorno para a coleta de material botânico, sendo utilizada metodologia usual de coleta e herborização de material botânico (Fidalgo \& Bononi 1989). As 11 coleções obtidas durante o presente estudo foram depositadas nos Herbários SP e UNIP (abreviações segundo Thiers et al. 2014). As coleções da Flora Fanerogâmica da Reserva Biológica de Paranapiacaba, depositadas no Herbário SP, também foram analisadas para a realização do presente estudo. As ilustrações dos frutos foram realizadas a partir de material coletado ou herborizado. Para algumas espécies foram analisadas coleções adicionais obtidas em outras localidades para a complementação das descrições devido à ausência de flores e ou frutos nas coleções referentes à área de estudo.

\section{Resultados}

\section{Malpighiaceae Juss.}

Lianas ou árvores, em geral um par de estípulas na base do pecíolo, raro epipeciolares caducas ou ausentes. Folhas simples, opostas, em geral elípticas,raras ovais ou obovais, presença de nectários extraflorais na base do pecíolo e ou na lâmina foliar, próximo à margem e ou às nervuras, raro ausentes. Inflorescência em racemos ou corimbos, estes solitários ou reunidos em panículas. Flores com 5 pétalas em geral amarelas, raro róseas, cálice com 5 sépalas em geral 8-glanduloso, sépalas posteriores e laterais biglandulosas, sépala anterior eglandulosa, raro 10-glanduloso, todos as sépalas biglandulosas, androceu contendo 10 estames férteis, distribuídos em dois verticilos de 5 estames cada, em geral semelhantes entre si, raro desiguais, conectivo obtriangular, arredondado ou linear, ultrapassando ou não as tecas, gineceu contendo três carpelos sincárpicos, cada um com um estilete. Frutos em geral do tipo samarídeo, contendo até três samários, cada samário com uma a quatro alas ou frutos do tipo drupa.

Chave de Identificação para as espécies de Malpighiaceae da Reserva Biológica do

Alto da Serra de Paranapiacaba

1. Árvore. Cálice 10-glanduloso. Fruto do tipo drupa 1. B. myricifolia

1. Liana. Cálice 8-glanduloso. Fruto do tipo samarídeo 
2. Flores com pétalas alaranjadas a avermelhadas após polinização. Samários contendo dois pares de alas laterais, duas maiores e duas menores e três cristas dorsais no núcleo seminífero ... 8. T. phlomoides

2. Flores com pétalas amarelas mesmo após a polinização. Samários contendo uma ala dorsal desenvolvida espessada na margem inferior, sem alas laterais ou uma ou duas alas laterais desenvolvidas, com uma ala dorsal reduzida, sem cristas dorsais no núcleo seminífero

3. Flores reunidas em corimbos solitários ou racemos. Samários contendo uma ou duas alas laterais

4. Um par de estípulas interpeciolares na base do pecíolo. Racemos, pedúnculo ca. $7 \mathrm{~mm}$ compr. Conectivo arredondado não ultrapassando as tecas. Samários contendo uma ala lateral orbicular

7. M. sepium

4. Um par de estípulas epipeciolares, próximo à lâmina. Corimbo solitário, pedúnculo ausente. Conectivo obtriangular ultrapassando as tecas. Samário contendo um par de alas laterais 6. H. fagifolia

3. Flores reunidas em panículas de corimbos. Samários contendo uma ala dorsal desenvolvida espessada na margem inferior, sem alas laterais

5. Pedúnculo ca. $2 \mathrm{~mm}$ compr. Pétalas com margem inteira. Pétala posterior maior que as demais. Samário com núcleo seminífero deltoide 2. H. intermedia

5. Pedúnculo ca. $4 \mathrm{~mm}$ ou ausente. Pétalas com margem denteada ou fimbriada. Pétala posterior igual ou menor que as demais. Samário com núcleo seminífero arredondado ou alongado

6. Face abaxial das folhas com indumento dourado, lâmina foliar com até 12 pares de nectários extraflorais entre as nervuras secundárias e a margem, base do pecíolo eglandulosa. Pedúnculo ca. $4 \mathrm{~mm}$ compr. Conectivo arredondado ..... 3. H. nitida

6. Face abaxial das folhas com indumento ferrugíneo ou castanho, lâmina foliar eglandulosa, um par de nectários extraflorais na base do pecíolo. Pedúnculo ausente. Conectivo linear

7. Face abaxial das folhas com indumento ferrugíneo. Conectivo não ultrapassando as tecas 5. H. thyrsoidea 7. Face abaxial das folhas com indumento castanho. Conectivo ultrapassando as tecas ..... 4. H. patens

\section{Byrsonima myricifolia Griseb., Vidensk. Meddel.} Naturhist. Foren. Kjøbenhavn: 125. 1875. Ilustração em Niedenzu (1928).

Figura 1a

Árvore, um par de estípulas intrapeciolares na base do pecíolo. Pecíolo 0,5-1,2 cm compr., folhas elípticas, lâmina foliar 3-8 × 1,1-3,2 cm, ambas as faces glabrescentes, indumento velutino castanho-claro a castanho-escuro, até 6 pares de glândulas localizadas entre as nervuras secundárias e a margem, pecíolo eglanduloso. Racemos $4-7 \mathrm{~cm}$ compr., pedúnculo ca. $4 \mathrm{~mm}$, pedicelo ca. $8 \mathrm{~mm}$, indumento castanho-escuro. Flores com cálice 10-glanduloso, elaióforos ca. 1,6 × $1 \mathrm{~mm}$; pétalas amarelas, margem levemente denteada, semelhantes entre si, limbo 5,1-5,5 × 4,3-5 mm, unha 2-2,5 mm; estames isomórficos, conectivo obtriangular ultrapassando as tecas, filetes ca. $2,5 \mathrm{~mm}$ compr., anteras ca. 1,6 × 0,8 mm; ovário ca. 1,2 mm compr., estiletes ca. 2,8 mm compr. Drupas 0,7-1 cm diâm., glabras de coloração vermelha quando maduras.

Floresce de dezembro a abril e frutifica de julho a setembro. Trata-se de uma espécie exclusiva de Floresta Atlântica com distribuição pelos Estados do Rio de Janeiro, São Paulo e Paraná (Mamede et al. 2015).

Material examinado: BRASIL. São Paulo: Santo André, Reserva Biológica do Alto da Serra de Paranabiacaba, 4-I-1919, F.C. Hoehne s.n. (SP2674); 4-III-1919, F.C. Hoehne s.n. (SP3017, SPF66385); 22-XII-1919, F.C. Hoehne s.n. (SP3588); 6-II-1920, A. Gehrt s.n. (SP3677); 23-XII-1920, F.C. Hoehne s.n. (SP4677); 4-IV-1922, A. Gehrt s.n. (SP8119); 29-IX-1928, D. Lemos s.n. (SP23803); 14-VII-1961, J. Mattos 9042 (SP); 17-18-II-1968, C. Moura s.n. (SP130260, SPF198797); 7-XII-1982, A.C. Filho 1106 (SP); 28-XII-1982, elev. 750-900 m, 23ㅇㄱ' S, 46 ${ }^{\circ} 19^{\prime}$ W, M. Carra \& A.C. Filho 8 (SP); 28-III-1983, M. 
Kirizawa et al. 902 (SP); 22-V-1984, M. Sugiyama \& E.A. Lopes 497 (SP).

Esta é a única espécie de Malpighiaceae ocorrente na Reserva Biológica de Paranapiacaba com hábito arbóreo e fruto do tipo drupa.

2. Heteropterys intermedia (A. Juss.) Griseb. in Mart, Fl. Bras. 12(1): 62. 1858. Ilustração em Sebastiani \& Mamede (2010).

Liana, estípulas ausentes. Pecíolo 0,6-2 cm compr., folhas elípticas, raro ovais, lâmina foliar 4,7-12,5 × 2,7-5,9 cm, face adaxial glabrescente, face abaxial serícea, indumento castanho-claro a castanhoescuro, até 6 pares de glândulas localizadas entre as nervuras secundárias e a margem, às vezes um par glândulas na base do pecíolo. Panículas 5,6-13,1 cm compr., com corimbos 1,5-1,6 cm, pedúnculo ca. $2 \mathrm{~mm}$, pedicelo 5-6 mm, indumento castanho-claro. Flores com cálice 8-glanduloso, elaióforos ca. 1,2 × $1 \mathrm{~mm}$; pétalas amarelas, margem inteira, pétala posterior maior que as demais, pétala posterior ca. $5,4 \times 2,3 \mathrm{~mm}$, unha ca. 2,2 mm compr., pétalas 4-4,6 $\times 2,8 \mathrm{~mm}$, unha 1,1-1,3 mm compr.; estames heteromórficos, conectivo arredondado não ultrapassando as tecas, filetes 2,7-2,8 mm compr., anteras ca. $1 \times 0,8 \mathrm{~mm}$; ovários ca. 1,2 mm compr., estiletes ca. 2,5 mm compr. Samários 0,9-2,5 × 0,5-1 cm, ala dorsal espessada na margem inferior, alas laterais ausentes, indumento castanho, núcleo seminífero deltóide.

Floresce de novembro a fevereiro e frutifica em abril. Apresenta ampla distribuição no Brasil, ocorrendo principalmente em áreas de Floresta Atlântica, nos Estados da Bahia e de toda a região Sudeste, além dos Estados do Paraná e Santa Catarina (Mamede et al. 2015), sendo também reportada para Argentina e Paraguai (Sebastiani \& Mamede 2010).

Material examinado: BRASIL. São PaUlo: Santo André, Reserva Biológica do Alto da Serra de Paranapiacaba, 28-III-1983, M. Kirizawa et al. 910 (SP); 8-I-2004, R. Sebastiani 18 (SP, UNIP); 2-II-2004, R. Sebastiani et al. 22 (SP, UNIP); 2-II-2004, R. Sebastiani et al. 23 (SP, UNIP); 2-II-2004, R. Sebastiani et al. 24 (SP, UNIP); 4-I-2011, G.G.N. Alves \& R. Sebastiani 1 (UNIP); 6-I-2011, G.G.N. Alves \& R. Sebastiani 2 (UNIP); 6-I-2011, G.G.N. Alves et al. 3 (UNIP).

Todas as coleções de Heteropterys intermedia (A. Juss.) Griseb. obtidas durante o presente estudo foram encontradas em áreas parcial ou intensamente degradadas, principalmente em bordas de mata, coincidindo com as observações feitas por Sebastiani $\&$ Mamede (2010). No que se refere à presença de elaióforos nas sépalas, as flores em geral são 8-glandulosas. No entanto, é possível numa mesma inflorescência encontrar algumas flores 2-glandulosas ou 10-glandulosas entre as demais. Este padrão foi relatado por Anderson (1981) como comum para espécies de muitos gêneros da família. Os filetes, estiletes e unhas das pétalas posteriores são alvos durante a antese, tornando-se avermelhados após a polinização.

De acordo com Sebastiani \& Mamede (2010), $H$. intermedia apresenta grande variabilidade morfológica, principalmente quanto aos caracteres vegetativos, como folhas membranáceas a cartáceas, lanceoladas a ovais, ápice agudo a cuspidado e margens inteiras a crenuladas. Por outro lado, as glândulas são conspícuas na margem da lâmina foliar e as flores e frutos não apresentam variações expressivas, exceto pelo número variável de elaióforos nas sépalas.

3. Heteropterys nitida (Lam.) D.C., Prodr. (D.C.) 1: 592. 1824. Foto em Anderson et al. (2006) Figura 1b

Liana, estípulas ausentes. Pecíolo 0,3-1,5 cm compr., folhas elípticas, lâmina foliar $7,2-13 \times 3,8-5 \mathrm{~cm}$, face adaxial glabrescente, face abaxial serícea, indumento dourado, até 12 pares de glândulas localizadas entre as nervuras secundárias e a margem, pecíolo eglanduloso. Panículas 3-10,5 cm compr., com corimbos ca. 2,4 cm compr., pedúnculo ca. $4 \mathrm{~mm}$ compr., pedicelo ca. $5 \mathrm{~mm}$ compr., indumento dourado. Flores com cálice 8-glanduloso, elaióforos ca. $2 \times 1,5 \mathrm{~mm}$; pétalas amarelas, margem denteada, pétala posterior levemente menor que as demais, pétala posterior ca. $4 \times 2 \mathrm{~mm}$, unha ca. $1,4 \mathrm{~mm}$ compr., pétalas laterais limbo ca. $4 \times 2 \mathrm{~mm}$, unha ca. 1,3 mm compr.; estames isomórficos, conectivo arredondado não ultrapassando as tecas, filetes 1,6-1,7 mm compr., anteras ca. $1 \times 0,6 \mathrm{~mm}$; ca. $1 \mathrm{~mm}$ compr., estilete ca. 1,5 mm compr. Samários 2-3,6 1-1,9 cm, cada samário com uma ala dorsal espessada na margem inferior, alas laterais ausentes, indumento castanho, núcleo seminífero arredondado.

Floresce em março e frutifica em agosto. Segundo Mamede et al. (2015), ocorre amplamente pelos 
Estados da Bahia, toda a região Sudeste, Paraná e Santa Catarina, tanto em áreas de Floresta Atlântica como em Cerrado.

Material examinado: BRASIL. São Paulo: Santo André, Reserva Biológica do Alto da Serra de Paranapiacaba, trilha que une a estação à Vila de Paranapiacaba, 25-III-2002, A.L.D. Benedito 62 (SP); 24-VIII-2006, R. Sebastiani \& D.S.C. Ito 109 (SP).

Difere das demais ocorrentes na Reserva Biológica de Paranapiacaba devido à presença de indumento dourado na face abaxial da folha.

4. Heteropterys patens (Griseb.) A. Juss., Arch. Mus. Hist. Nat. 3: 437. 1843. Ilustração em Amorim (2003a).

Figura 1c

Liana, estípulas ausentes. Pecíolo 1,5-3,5 cm compr., folhas elípticas, lâmina foliar 5,3-19 × 4-10,2 cm, face adaxial glabrescente, face abaxial serícea, indumento castanho-claro a castanho-escuro, lâmina foliar e pecíolo eglandulosos. Panículas 5-9 cm compr., com corimbos ca. $2 \mathrm{~cm}$ compr., pedúnculo ausente, pedicelo 8-10 mm compr., indumento ferrugíneo. Flores com cálice 8-glanduloso, elaióforos ca. $2 \times 1 \mathrm{~mm}$; pétalas amarelas, margem fimbriada, limbo 5,5-7 × 1,5-2 mm, unha ca. 2,3 mm; estames heteromórficos, conectivo linear ultrapassando as tecas, filetes $2,5-3,1 \mathrm{~mm}$ compr., anteras 1,2-1,5 × 0,5-0,6 mm; ovário ca. $1,2 \mathrm{~mm}$ compr., estiletes ca. $4 \mathrm{~mm}$ compr. Samários 3,7-6,5 $\times 3,2-7,5 \mathrm{~cm}$, ala dorsal espessada na margem inferior, alas laterais ausentes, indumento ferrugíneo, núcleo seminífero arredondado.

Floresce em maio. Apresenta distribuição restrita aos Estados de São Paulo e Rio de Janeiro, em áreas de Floresta Atlântica, sendo considerada quase ameaçada quanto ao risco de extinção (Mamede et al. 2015).

Material examinado: BRASIL. São PAulo: Santo André, Reserva Biológica do Alto da Serra de Paranapiacaba, descida da Estrada Velha, 8-V-1923, A. Gehrt s.n. (SP 8371).
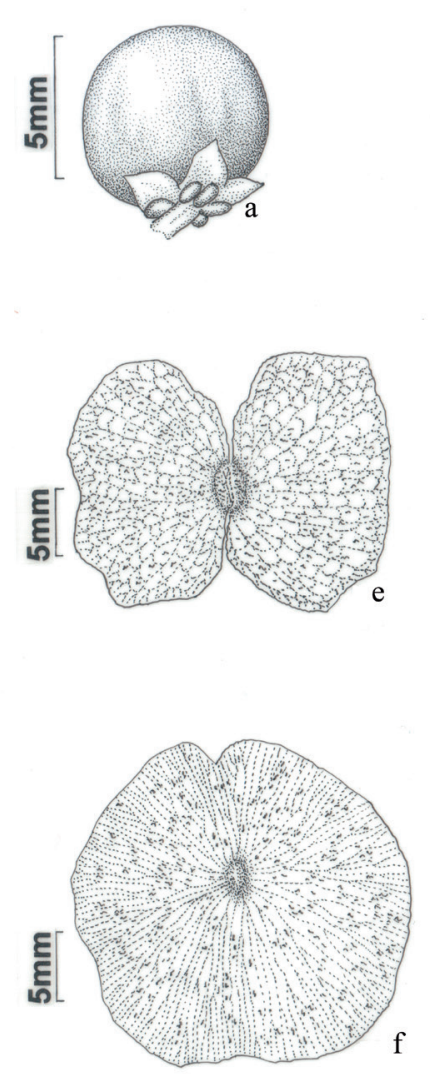
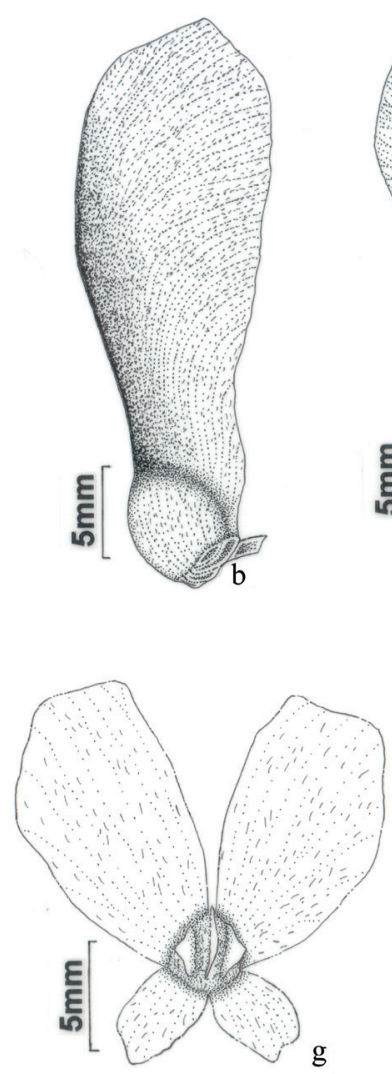
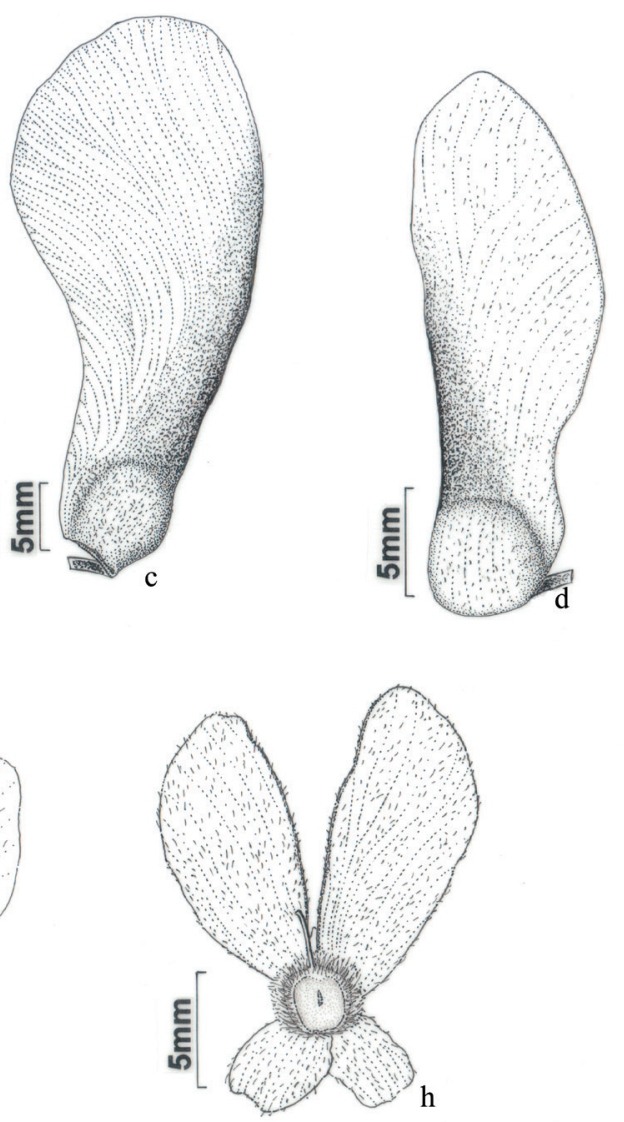

Figura 1. Frutos. a. Byrsonima myricifolia Griseb. b. Heteropterys nitida (Lam.) D.C. c. H. patens (Griseb.) A. Juss. d. H. thyrsoidea (Griseb.) A. Juss. e. Hiraea fagifolia (D.C.) A. Juss. f. Mascagnia sepium (A. Juss.) Griseb. g-h. Tetrapterys phlomoides (Spreng.) Nied.

Figure 1. Fruits. a. Byrsonima myricifolia Griseb. b. Heteropterys nitida (Lam.) D.C. c. H. patens (Griseb.) A. Juss. d. H. thyrsoidea (Griseb.) A. Juss. e. Hiraea fagifolia (D.C.) A. Juss. f. Mascagnia sepium (A. Juss.) Griseb. g-h. Tetrapterys phlomoides (Spreng.) Nied 
Material adicional examinado: BRASIL. S̃̃o PAULO: Ubatuba, Picinguaba, estrada da Casa de Farinha, 31-VII-1995, A. Takahasi \& C.S.C. Bencke 132 (SP). Rio de JANEIRo: Nova Iguaçu, Reserva Biológica de Tinguá, 10-II-1994, G.V. Somner et al. 778 (SP); Rio de Janeiro, Parque Nacional da Tijuca, Morro do Cochrane, 21-XII- 1999, A.M. Amorim \& C.A.L. Oliveira 3216 (SP).

De acordo com Amorim (2003a), Heteropterys patens (Griseb.) A. Juss. apresenta estípulas medindo cerca de $0,3 \mathrm{~mm}$ de comprimento, caducas, folhas contendo glândulas dispostas na margem da lâmina e na base do pecíolo. O fato das estípulas dessa espécie serem caducas justifica a ausência de tais estruturas na coleção examinada referente à área de estudo. Quanto aos nectários na margem da lâmina foliar, estes podem ser de difícil visualização em espécies com folhas muito pilosas, o que provavelmente dificultou a visualização de tais estruturas na única coleção disponível para o presente estudo.

5. Heteropterys thyrsoidea (Griseb.) A. Juss., Arch. Mus. Hist. Nat. 3: 436. 1843. Ilustração em Amorim (2003b).

Figura 1d

Liana, um par de estípulas interpeciolares na base do pecíolo. Pecíolo 0,5-2 cm compr., folhas elípticas, lâmina foliar 7,5-12,5 × 3,8-7,2 cm, face adaxial glabrescente, face abaxial tomentosa, indumento ferrugíneo, lâmina foliar eglandulosa, um par de nectários extraflorais na base do pecíolo. Panículas 5,5-8 cm compr., com corimbos ca. 2 cm compr., pedúnculo ausente, pedicelo ca. $6 \mathrm{~mm}$, indumento ferrugíneo. Flores com cálice 8-glanduloso, elaióforos ca. 1,5 $\times 1 \mathrm{~mm}$; pétalas amarelas, margem fimbriada, desiguais entre si, pétala posterior mais intensamente fimbriada e menor que as demais, pétala posterior limbo ca. $4 \times 2 \mathrm{~mm}$, unha ca. $1 \mathrm{~mm}$ compr., pétalas laterais ca. $5 \times 3 \mathrm{~mm}$, unha ca. 0,5 $\mathrm{mm}$ compr.; estames isomórficos, conectivo linear não ultrapassando as tecas, filetes ca. $0,8 \mathrm{~mm}$ compr., anteras $1,8 \times 0,8 \mathrm{~mm}$; ovário ca. $1 \mathrm{~mm}$ compr., estiletes ca. 1,5 mm compr. Samários 2-3 × 1-1,1 cm, ala dorsal espessada na margem inferior, alas laterais ausentes, indumento ferrugíneo, núcleo seminífero alongado.

Floresce em março a maio. Segundo Mamede et al. (2015), ocorre exclusivamente em áreas de Floresta Atlântica do Estado de São Paulo, sendo considerada em risco de extinção.
Material examinado: BRASIL. São Paulo: Santo André, Reserva Biológica do Alto da Serra de Paranapiacaba, 16-V-1922, A. Gehrt s.n. (SP 8118); 29-V-1969, J. Mattos 15432 (SP); 28-III-1984, picada 1, M. Sugiyama \& M. Kirizawa 470 (SP).

Material adicional examinado: BRASIL. São PAULO: São Paulo, Parque Estadual da Serra do Mar, Núcleo Curucutu, trilha para o rio Embu-Guaçu, 17-III-2000, A.M. Amorim et al. 3362 (SP); trilha do Marco, 1-VI-1999, A.M. Amorim et al. 3085 (SP).

Não foram observadas glândulas na lâmina foliar nas coleções referentes à área de estudo. No entanto, de acordo com Amorim (2003b), Heteropterys thyrsoidea (Griseb.) A. Juss. apresenta lâmina foliar com face abaxial contendo glândulas esparsas, encobertas pelos tricomas, o que provavelmente dificultou a visualização dessas estruturas no presente estudo.

6. Hiraea fagifolia (DC.) A. Juss., Ann. Sci. Nat. 13: 258. 1840. Ilustração em Anderson et al. (2006). Figura 1e

Liana, um par de estípulas epipeciolares, próximo à lâmina. Pecíolo 0,3-2 cm compr., folhas obovais a elípticas, lâmina foliar 4,8-2,1 × 1,2-5,5 cm, ambas as faces glabrescentes, indumento castanho-claro, lâmina e pecíolo eglanduloso. Corimbos solitários 2,6-2,8 cm compr., pedúnculo ausente, pedicelo 9-25 mm compr., indumento castanho-claro. Flores com cálice 8-glanduloso, sépalas posteriores e laterais biglandulosas, sépala anterior eglandulosa, elaióforos ca. $0,5 \times 0,5 \mathrm{~mm}$; pétalas amarelas, margem fimbriada, pétala posterior levemente menor que as demais, pétala posterior limbo ca. $7 \times 4,8 \mathrm{~mm}$, unha ca. 2,3 mm, pétalas laterais limbo ca. 7,5 $66 \mathrm{~mm}$, unha ca. 1,6 mm compr.; estames levemente heteromórficos, conectivo obtriangular ultrapassando as tecas, filetes 1,5-2,7 mm compr., anteras 1-1,3 × $1 \mathrm{~mm}$; ovário ca. $1 \mathrm{~mm}$ compr., estiletes ca. $3 \mathrm{~mm}$ compr. Samários $2,6 \times 3,5 \mathrm{~cm}$, alas laterais membranáceas, uma ala dorsal reduzida, indumento castanho-claro, núcleo arredondado.

Floresce em agosto. Apresenta ampla distribuição, ocorrendo nos Estados do Acre, Rondônia, Bahia, Paraná e toda a região Sudeste, em áreas de Cerrado, Floresta Atlântica e formações amazônicas (Mamede et al. 2015).

Material examinado: BRASIL. SÃo PAULO: Município de Santo André, Distrito de Paranapiacaba, Trilha do 
Vale do Rio Mogi, 24-VIII-2006, R. Sebastiani \& D.S.C. Ito 108 (SP).

Material adicional examinado: BRASIL. São Paulo: Cananéia, Parque Estadual Ilha do Cardoso, 3-XII-1985, I.C.C. Macedo, F. Barros \& M.M.F. Melo 74 (SP).

Apesar de sua ampla distribuição já relatada por Mamede et al. (2015), foi obtida apenas uma coleção na Trilha do Vale do Rio Mogi, nos limites da Reserva Biológica de Paranapiacaba. Esta espécie é facilmente reconhecida pela presença de estípulas epipeciolares e samário contendo duas alas laterais, caracteres estes não observados nas outras espécies de Malpighiaceae ocorrentes na área de estudo, mas diagnósticos do gênero Hiraea.

7. Mascagnia sepium (A. Juss.) Griseb. in Mart., Fl. Bras. 12(1): 96. 1858. Ilustração em Jussieu (1832). Figura 1f

Liana, um par de estípulas interpeciolares na base do pecíolo. Pecíolo 0,5-1,5 cm compr., folhas elípticas, lâmina foliar 3-7 × 2-3 cm, ambas as faces esparsamente seríceas, indumento castanho-claro, lâmina e pecíolo eglandulosos. Racemos $2-5,5 \mathrm{~cm}$ compr., pedúnculo ca. $7 \mathrm{~mm}$ compr., pedicelo ca. $5 \mathrm{~mm}$ compr., indumento ferrugíneo. Flores com cálice 8 -glanduloso, elaióforos ca. 1,8 $\times 1 \mathrm{~mm}$; pétalas amarelas, margem levemente denteada, pétala posterior menor que as demais, limbo ca. $4,8 \times 2 \mathrm{~mm}$, unha ca. $1 \mathrm{~mm}$, pétalas laterais limbo 5-5,5 $\times$ 2,8-3 mm, unha 1,3-1,5 mm compr.; estames levemente heteromórficos, conectivo arredondado não ultrapassando as tecas, filetes 2,3-2,7 mm compr., anteras $0,8-1 \times 0,6-0,7 \mathrm{~mm}$; ovário ca. $1,3 \mathrm{~mm}$ compr., estiletes ca. 3,2 mm compr. Samário 0,4-2 cm diâm., ala lateral orbicular, ala dorsal reduzida, indumento castanho-claro, núcleo seminífero arredondado.

Floresce em novembro e dezembro e frutifica em dezembro. Apresenta ampla distribuição, ocorrendo desde o Estado do Piauí até o Estado de São Paulo, passando também por Mato Grosso e Goiás, em áreas de Cerrado, Floresta Atlântica e Caatinga (Mamede et al. 2015).

Material examinado: BRASIL. São PAULO: Município de Santo André, Distrito de Paranapiacaba, 20-XI-1981, M. Kirizawa et al. 593 (SP); 7-XII-1982, A.C. Filho \& M. Carra 1148 (SP); 20-XI-1984, M. Kirizawa \& T.P. Guerra 1343 (SP); 18-XII-2003, R. Sebastiani 14 (SP); 18-XII-2003, R. Sebastiani 15 (SP).
Esta espécie distingue-se claramente das demais espécies de Malpighiaceae ocorrentes na Reserva Biológica de Paranapiacaba por apresentar samário contendo uma ala lateral orbicular.

8. Tetrapterys phlomoides (Spreng.) Nied. in Engl., Pfanzenreich 141: 208. 1928. Ilustração em Niedenzu (1928).

Figura 1 g-h

Liana, um par de estípulas interpeciolares na base do pecíolo. Pecíolo 1-2,5 cm compr., folhas elípticas a ovais, lâmina foliar 6-10 × 4,2-7,5 cm, ambas as faces tomentosas, indumento castanho-claro, um par de glândulas na base da lâmina, um par de nectários extraflorais na base do pecíolo. Corimbos reunidos em panícula, $6-8 \mathrm{~cm}$ compr., pedúnculo 4-6 mm compr., pedicelo 5-6 mm compr., indumento castanho-claro. Flores com cálice 8-glanduloso, elaióforos ca. $2,5 \times 1 \mathrm{~mm}$; pétalas alaranjadas a avermelhadas, margem levemente denteada, pétala posterior levemente menor que as demais, pétala posterior limbo ca. $8 \times 3,5 \mathrm{~mm}$, unha ca. $3 \mathrm{~mm}$ compr., pétalas laterais limbo 7-9 $\times 5 \mathrm{~mm}$, unha ca. 2 $\mathrm{mm}$ compr.; estames isomórficos, conectivo linear não ultrapassando as tecas, filetes ca. $3 \mathrm{~mm}$, anteras ca. $1,5 \times 0,9 \mathrm{~mm}$; ovário ca. 2,5 mm compr., estiletes ca. 3,5 mm compr. Samários contendo 2 pares de alas laterais, duas maiores ca. $1,8 \times 0,9 \mathrm{~cm}$, e duas menores ca. $1,5 \times 0,8 \mathrm{~cm}$, três alas dorsais reduzidas, indumento castanho-claro, núcleo seminífero arredondado.

Frutifica em junho. Trata-se de uma espécie com ampla distribuição, ocorrendo em áreas de Caatinga, Cerrado, Floresta Atlântica em Estados das regiões Nordeste, Centro-Oeste, Sudeste e Sul do Brasil (Mamede et al. 2015).

Material examinado: BRASIL. São Paulo: Santo André, Distrito de Paranapiacaba, Reserva Biológica do Alto da Serra de Paranapiacaba, próximo à entrada da trilha da pontinha, trecho da subida do Morro do João Dias, 10-VI-2003, R.S. Bianchini et al. 1569 (SP).

Material adicional examinado: BRASIL. S̃̃o PAULO: São Paulo, Araçá, 6-V-1920, F.C. Hoehne 3926 (SP); Parque Estadual das Fontes do Ipiranga, Instituto de Botânica, na entrada da Seção de Sementes, em frente à Seção de Fisiologia, 23-IV-2004, R. Sebastiani 66 (SP).

Esta espécie é caracterizada pela presença de folhas com ambas as faces tomentosas, flores com 
pétalas alaranjadas a avermelhadas e samário contendo dois pares de alas laterais.

\section{Discussão}

Para a Reserva Biológica do Alto da Serra de Paranapiacaba foram reconhecidos cinco gêneros e oito espécies: Byrsonima myricifolia Griseb., Heteropterys intermedia (A. Juss.) Griseb., H. nitida (Lam.) Kunth, H. patens (Griseb.) A. Juss., H. thyrsoidea (Griseb) A. Juss., Hiraea fagifolia (D.C.) A. Juss., Mascagnia sepium (A. Juss.) Griseb. e Tetrapterys phlomoides (Spreng.) Nied. A espécie Stigmaphyllon arenicola C.E. Anderson, anteriormente citada para a Reserva Biológica de Paranapiacaba por Kirizawa et al. (2009), não foi incluída no presente estudo por não ocorrer nos limites da Reserva Biológica de Paranapiacaba e por não terem sido localizadas coleções provenientes da área de estudo. Esse táxon pode ter sido erroneamente incluído na lista de Kirizawa et al. (2009) e possivelmente ocorre fora dos limites da Reserva, mais próximo ao Município de Cubatão, já que é uma espécie comum em áreas de restinga (Anderson 1993). Por outro lado, H. fagifolia foi considerada no presente estudo como uma nova ocorrência para a Reserva Biológica de Paranapiacaba, uma vez que não havia sido citada anteriormente por Kirizawa et al. (2009).

Do total de espécies de Malpighiaceae para o Brasil, 75 distribuem-se também pelas diversas fitofisionomias de Floresta Atlântica no Estado de São Paulo. O número de espécies registrado no presente estudo para a Reserva Biológica de Paranapiacaba é próximo ao que tem sido relatado para outras áreas de Floresta Atlântica protegidas do Estado de São Paulo. Mamede (1992) aponta a ocorrência de 10 espécies de Malpighiaceae para a Ilha do Cardoso, das quais três foram aqui citadas, $H$. intermedia, $H$. nitida e H. fagifolia. Garcia \& Pirani (2005) também relacionam oito espécies de Malpighiaceae para o Núcleo Curucutu (Parque Estadual da Serra do Mar), dentre as quais $B$. myricifolia, $H$. intermedia, $H$. nitida, $H$. thyrsoidea e $H$. fagifolia, também são aqui mencionadas para a Reserva Biológica de Paranapiacaba. Mamede (1984) aponta a ocorrência de doze espécies de Malpighiaceae para a Reserva do Parque Estadual das Fontes do Ipiranga (Município de São Paulo), das quais quatro são aqui relatadas para a Reserva Biológica de Paranapiacaba (H. intermedia, H. fagifolia, M. sepium e T. phlomoides).
Das oito espécies aqui estudadas duas são consideradas ameaçadas de extinção (Mamede et al. 2015) e constam no Livro Vermelho das Espécies Vegetais Ameaçadas do Estado de São Paulo. Heteropterys patens (Griseb.) A. Juss. e H. thyrsoidea (Griseb.) A. Juss. estão na categoria vulnerável, uma vez que apresentam distribuição geográfica mais restrita que as demais e ou exclusivamente em Unidades de Conservação (Mamede et al. 2007). Ao contrário do que se observa para $H$. patens, cuja coleção para a Reserva Biológica de Paranapiacaba data de 1923, Villagra (2012) menciona a ocorrência recente de $H$. thyrsoidea para esta área em seu estudo das comunidades trepadeiras na Floresta Atlântica de Santo André.

Alguns autores têm destacado a importância da Reserva Biológica de Paranapiacaba para a conservação da biodiversidade (Mendes \& Sebastiani 2012, Lopes et al. 2009). Os dados aqui obtidos reforçam esse fato e demonstram a necessidade de mais estudos nessa importante unidade de conservação no Estado de São Paulo.

\section{Agradecimentos}

Ao ilustrador Klei Souza, pela finalização das ilustrações; aos curadores dos herbários PMSP, SP, SPF e UNIP; à administração da Reserva Biológica do Alto da Serra de Paranapiacaba pela concessão da autorização de visitação e de coleta de material botânico; ao Núcleo de Pesquisa Curadoria do Herbário e ao Laboratório de Taxonomia da Universidade de São Paulo pelo uso das lupas para ilustração; à Universidade Paulista, pela concessão de Bolsa de Iniciação Científica à primeira autora.

\section{Literatura citada}

Amorim, A.M. 2003a. The anomalous-stemmed species of Heteropterys subsect. Aptychia (Malpighiaceae). Brittonia 55: 127-145.

Amorim, A.M. 2003b. Estudos taxonômicos em Heteropterys (Malpighiaceae). Tese de doutorado. Universidade de São Paulo, São Paulo, SP.

Anderson, C.E. 1993. Novelties in Stigmaphyllom (Malpighiaceae) from South America. Contributions from the University of Michigan Herbarium 19: 415-429.

Anderson, W.R. 1979. Floral conservatism in neotropical Malpighiaceae. Biotropica 11: 219-223.

Anderson, W.R. 1981. Malpighiaceae. In: B. Maguire (ed.). The Botany of the Guayana Highland - Part XI (Memoirs of the New York Botanical Garden 32: 21-305. 
Anderson, W.R. 2013. Origins of Mexican Malpighiaceae. Acta Botanica Mexicana 104: 107-156.

Anderson, W.R., Anderson, C. \& Davis, C.C. 2006. Malpighiaceae. Disponível em http://herbarium.lsa. umich.edu/malpigh/index.html (acesso em 27-II-2015).

Coutinho, L.M. 2009. O conceito de Mata Atlântica. In: M.I.M.S. Lopes, M. Kirizawa \& M.M.R.F. Melo (eds.). Patrimônio da Reserva Biológica do Alto da Serra de Paranapiacaba. A Antiga Estação Biológica do Alto da Serra. Governo do Estado de São Paulo, Secretaria do Meio Ambiente, Instituto de Botânica, pp. 99-104.

Davis, C.C. \& Anderson, W.R. 2010. A complete generic phylogeny of Malpighiaceae inferred from nucleotide sequence data and morphology. American Journal of Botany 97: 2031-2048.

Fidalgo, O. \& Bononi, V.L.R. 1989. Técnicas de coleta, preservação e herborização de material botânico. Governo do Estado de São Paulo, Secretaria do Meio Ambiente.

Garcia, R.J.F. \& Pirani, J.R. 2005. Análise florística, ecológica e fitogeográfica do Núcleo Curucutu, Parque Estadual da Serra do Mar (São Paulo-SP), com ênfase nos campos juntos à crista da Serra do Mar. Hoehnea 32: $1-48$

Gutjahr, M.R. \& Tavares, R. 2009. Clima. In: M.I.M.S. Lopes, M. Kirizawa \& M.M.R.F. Melo (eds.). Patrimônio da Reserva Biológica do Alto da Serra de Paranapiacaba. A Antiga Estação Biológica do Alto da Serra. Governo do Estado de São Paulo, Secretaria do Meio Ambiente, Instituto de Botânica, pp. 39-51.

Jussieu, A. 1832. Malpighiaceae. In: A.F.P. Saint-Hilaire (ed.). Flora brasilie meridionalis. A. Belin, Paris 3: 1-86.

Kirizawa, M., Sugyama, M., Lopes E.A \& Custódio Filho A. 2009. Fanerógamas: Plantas com flores. In: M.I.M.S. Lopes, M. Kirizawa \& M.M.R.F. Melo (eds.). Patrimônio da Reserva Biológica do Alto da Serra de Paranapiacaba: antiga Estação Biológica do Alto da Serra. Governo do Estado de São Paulo, Secretaria do Meio Ambiente, Instituto de Botânica, pp. 291-350.
Lopes, M.I.M.S., Kirizawa, M. \& Melo, M.M.R.F. (eds.). 2009. Patrimônio da Reserva Biológica do Alto da Serra de Paranapiacaba: antiga Estação Biológica do Alto da Serra. Governo do Estado de São Paulo, Secretaria do Meio Ambiente, Instituto de Botânica.

Mamede, M.C.H. 1984. Flora Fanerogâmica da Reserva do Parque Estadual das Fontes do Ipiranga (São Paulo, Brasil). 125 - Malpighiaceae. Hoehnea 11: 108-113.

Mamede, M.C.H. 1992. Malpighiaceae In: Flora Fanerogâmica da Ilha do Cardoso. M.M.R.F. Melo, F. Barros, S.A.C. Chiea, M. Kirizawa, S.L. JungMendaçolli, M.G.L. Wanderley (eds.). Instituto de Botânica, São Paulo 3: 73-88.

Mamede, M.C.H., Souza, V.C., Prado, J., Barros, F., Wanderley, M.G.L. \& Rando, J.G. 2007. Livro vermelho das espécies vegetais ameaçadas do Estado de São Paulo. Instituto de Botânica de São Paulo.

Mamede, M.C.H., Sebastiani, R., Almeida, R.F., Francener, A, Amorim, A.M.A. 2015. Malpighiaceae. In: Lista de Espécies da Flora do Brasil. Jardim Botânico do Rio de Janeiro. Disponível em http://floradobrasil. jbrj.gov.br/jabot/floradobrasil/FB155 (acesso em: 27-II-2015).

Mendes, Z.R. \& Sebastiani, R. 2012. Cactaceae from Reserva Biológica do Alto da Serra de Paranapiacaba, Santo André, São Paulo State, Brazil. Hoehnea 39: 409-419.

Niedenzu, F. 1928. Malpighiaceae. In: A. Engler, (ed.). Das Pflanzenreich. IV. 141: 1-870.

Sebastiani, R. \& Mamede, M.C.H. 2010. Estudos taxonômicos em Heteropterys Kunth subsect. Stenophyllarion (Malpighiaceae) no Brasil. Hoehnea 37: 337-366.

Thiers, B. 2014. Index herbariorum: a global directory of public herbaria and associated staff. New York Botanical Garden'sVirtual Herbarium. Disponível em http:// sweetgum.nybg.org/ih/ (acesso em 18-VIII- 2014).

Villagra, B. L. P. 2012. Estrutura da comunidade de trepadeiras em Mata Atlântica, Santo André, SP, Brasil. Tese de doutorado. Instituto de Botânica da Secretaria de Estado do Meio Ambiente. 